variations in airways resistance did not mention much of the carefully documented early studies of this phenomena and of its interrelations with histamine responses and with circadian variations in direct hypersensitivity responses. ${ }^{26} 27$ Many other authors have also failed to explore the rather elusive publications on chronobiology published over the past two decades.

Those who have not taken an interest in the relevance of rhythmicity to their clinical or biological interests may find useful the reviews from those groups who have. The reports of some of the symposia they attended provide a route to many of the earlier publications. ${ }^{67714242628.33}$ In the future these may be seen to have an importance not perceived at the time. A leading article in the $B M \mathcal{F}$ in 1979 could refer to only a handful of reports correlating immunity and biological rhythmicity; now a library search would yield more than $400 .{ }^{3}$

MARTIN S KNAPP

Senior research fellow

Roy POWNALL

Senior scientist

Unit of Medical Information Technology,

Department of Obstetrics and Gynaecology,

University Hospital,

Nottingham NG7 2UH

1 Kreiger DT. Rhythms in CRF, ACTH and corticosteroids. In: Kreiger DT, ed. Endocrine rhythms. New York: Raven Press, 1979:123-42.

Bertouch JV, Roberts-Thomson PJ, Bradley J. Diurnal

by monoclonal antibodies. BrMed f 1983;286:1171-2.

study with monoclonal antibodies. Br Med F 1983;286:1773-5.
stchian

Pownall R, Ward C, Knapp MS. Circadian variation of helper vi F, Cannon C, Blum JP, Reinberg A, Mathe G. Large amp

suppressor ratio of peripheral blood lymphocytes. Lancet 1983;ii: $462-3$. ownall R, Knapp MS. Immune responses have rhythms: are they important? Immunology Today

7 Knapp MS. Chronobiology: a subject of importance to the rheumatologist? $\mathrm{Br} f \mathrm{Clin}$ Pract

a Pownall R. Biological rhythms in cell-mediated Clin Pract 1984;38 symp suppl 33):20-3.

作

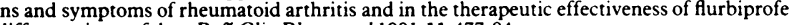

9 Knapp MS, Cove-Smith JR, Dugdale R, Mackenzie N, Pownall R. Possible effect of time on renal allograft rejection. BrMed $\mathcal{F} 1979 ; \mathrm{i}: 75-7$.

10 Abo T, Kawate T, Itoh K, Kumagai K. Studies on the bioperiodicity of the immune response $\mathrm{I}$ Circadian rhythms of human $\mathrm{T}, \mathrm{B}$ and $\mathrm{K}$ cell traffic in the peripheral blood. $\mathcal{f}$ Immunol 1981;126:1360-3.

11 Shaw AFB. The diurnal tides of the leucocytes of man. Journal of Pathology and Bacteriology

12 Eskola J, Frey H, Molnar G, Soppi E. Biological rhythm of cell-mediated immunity in man. Clin

13 Tavadia HB, Fleming KA, Hume PD, Simpson HW. Circadian rhythmicity of human plasma cors $E$. immunology. Am $\mathcal{f}$ Anat 1983;168:467-517.

15 Pownall R, Knapp MS. Circadian rhythmicity of delayed hypersensitivity to oxazalone in the rat Clinical Science and Molecular Medicine 1978;54:447-9.

16 Cove-Smith JR, Kabler P, Pownall R, Knapp MS. Circadian variation in an immune response in man. BrMed f 1978;ii:253-4.

$17 \mathrm{Knapp}$ MS, Pownall R. Circadian rhythm in immune responses and in the effects of glucocorticoids. Allergologie 1980;3:5226-30.

18 Pownall R. Knapp MS. A circadian study of corticosteroid suppression of delayed hyper-

19 Labrecque G, Dore F, Laperriere A, Perusse F, Belanger PM. Chronopharmacology IIvariations in the carrageenin-induced oedema, in the action of the plasma levels of indo1979:231-8.

20 de Vecchi A, Cantaluppi A, Ponticelli C, Halberg F, Southern RB. Circaseptan rhythmic aspects of rejection in treated patients with kidney transplants. In: Walker C, Winget CM, Soliman KFA, eds. Chronopharmacology and chronotherapeutics. Florida: $A$ and $M$ University

Foundation, 1981:339-54.
21 Levi FA, Canon CH, Blum JP, et al. Circadian rhythms in circulating lymphocyte subsets in healthy men: a 100 -fold variation may be physiologic. In: Reinberg A, Smolensky M, Labreque G, eds. 1st Montreux international symposium on biological rhythms and medications. Oxford: Pergamon Press (in press)

22 Knapp MS, Keane PM, Wright JG. Circadian rhythm of plasma 11-hydroxycorticosteroids in depressive illness, congestive heart failure, and Cushing's syndrome.

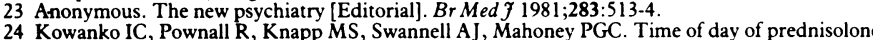
administration in rheumatoid arthritis. Ann Rheum Dis 1982;41:447-5

25 Liu T, Cavallim M, Halberg F, et al. Toward a circaseptan and circadian cyclosporine chronotherapy of rats with segmental pancreatic allografts. In: Reinberg A, Smolensky M, Labreque $\mathrm{G}$, eds. Ist Montreux international symposium on biological rhythms and medications. Oxford Pergamon Press (in press)

26 Reinberg A, Smolensky MH. Biological rhythms and medicine. Berlin: Springer-Verlag, 1983. 27 Barnes PJ. Nocturnal asthma: mechanisms and treatment. Br Med F 1983;288:1397-8. 28 Scheving LE, Halberg F, Pauly JE, eds. Chronobiology. Tokyo: Igaku Shoin, 1974. Walker CA, Winget CM, Soliman KFA, eds. Chronopharmacology and chronotherapeutics. Florida: $A$ and $M$ University Foundation, 1981:1-411.

cheving LE, M

I More-Ede MC, Sulzman FM, Fuller CA. The clocks that time us. Cambridge, USA. University of Harvard Press, 1982

32 Minors JM, Waterhouse DS. Circadian rhythm and the human. Bristol: Wright, 1981.

33 Anonymous. Chronotherapeutics, a new clinical science [Editorial]. Br Med F 1978;i:1376.
Drug interactions and $\beta$ blockers

$\beta$ adrenoceptor antagonists interact with many drugs with which they may be given simultaneously, but neither the frequency nor the clinical importance of most of these interactions has been clearly established. An interaction may change the response to either the $\beta$ blocker or the other drug or potentiate an unwanted effect that they share. The mechanism may be either pharmacokinetic or pharmacodynamic.

Pharmacokinetic interactions result from changes in hepatic oxidative drug metabolism. ${ }^{1}$ They occur mainly with the more lipid soluble $\beta$ blockers such as propranolol and metoprolol, which are extensively metabolised and have a high first pass clearance ${ }^{1}$; to a less extent with acebutolol and oxprenolol; and not at all with atenolol, sotalol, nadolol, and pindolol, which are eliminated unchanged by the kidney. Enzyme inducing drugs increase the clearance of metabolised $\beta$ blockers and reduce the bioavailability of those with a high first pass metabolism. ${ }^{2}$ Thus cimetidine increases the bioavailability of propranolol and metoprolol. ${ }^{34}$ The clearance of extensively metabolised $\beta$ blockers is also influenced by hepatic blood flow. This is the mechanism by which hydralazine reduces the first pass clearance of propranolol and metoprolol, increasing the plasma concentrations when these drugs are given by mouth. ${ }^{56}$ The changes in the blood concentration of $\beta$ blockers that result are, however, usually small and clinically unimportant.

$\beta$ blockers can themselves reduce the clearance of other drugs, both by inhibiting hepatic oxidative metabolism and by reducing hepatic blood flow secondary to the fall in cardiac output which they produce. ${ }^{1}$ Inhibition of drug metabolism occurs mainly with the extensively metabolised lipid soluble $\beta$ blockers, propranolol and metoprolol, and the fall in hepatic blood flow is greatest with $\beta$ blockers without intrinsic sympathomimetic activity. Propranolol and metoprolol reduce the clearance of lignocaine by both mechanisms ${ }^{78}$ and may produce lignocaine toxicity. ${ }^{9}$ Propranolol increases the blood concentrations of chlorpromazine by inhibiting its metabolism, an interaction which may explain earlier reports of a beneficial effect of propranolol in schizophrenic patients receiving chlorpromazine. ${ }^{10}$ Propranolol ${ }^{112}$ and possibly metoprolol, but not atenolol, ${ }^{13}$ inhibit the metabolism of coumarin anticoagulants. The effect on prothrombin time proved to be small in healthy volunteers, but it might be important in fully anticoagulated patients.

Pharmacodynamic interactions with $\beta$ blockers are usually more important than the pharmacokinetic interactions, and most can be predicted from the known pharmacological effects of the interacting drugs. Thus $\beta$ blockers potentiate the unwanted effects of many antiarrhythmic drugs, increasing the risk of myocardial depression, cardiac failure, hypotension, bradycardia, atrioventricular block, and asystole. Clinically important interactions have been reported with verapamil,,${ }^{14}$ disopyramide, ${ }^{15}$ lignocaine, ${ }^{9}$ and tocainide, ${ }^{16}$ and potentiation of the negative inotropic effect of other class I antiarrhythmic agents should be expected. In patients whose cardiac function is already impaired the combination of nifedipine and a $\beta$ blocker can produce severe hypotension and heart failure. ${ }^{17}$

Sotalol differs from other $\beta$ blockers in having class III antiarrhythmic activity at therapeutic doses. Thus it prolongs the Q-T interval and may increase the risk of ventricular arrhythmias. This risk appears to be greater in patients with hypokalaemia induced by diuretics ${ }^{18}$ and sotalol is perhaps not a suitable $\beta$ blocker for use with a thiazide diuretic.

The antihypertensive effect of $\beta$ blockers is antagonised by 
several non-steroidal anti-inflammatory drugs. ${ }^{19} 20$ This may be due partly to fluid retention, but inhibition of prostaglandin synthesis is probably more important. The interaction has been reported with many $\beta$ blockers and is probably common to all. It is best documented with indomethacin but may not occur with all non-steroidal anti-inflammatory drugs. For example, sulindac, which inhibits the systemic but not the renal synthesis of prostaglandins, does not appear to alter the blood pressure in patients taking atenolol. ${ }^{21}$

$\beta$ blockers potentiate the postural hypotensive effect of the first dose of prazosin, probably by preventing reflex tachycardia. ${ }^{22}$ They potentiate the hypertensive response to withdrawal of clonidine ${ }^{23}$ and may occasionally be responsible for severe hypertension in patients taking large doses of sympathomimetic amines such as phenylephrine and phenylpropanolamine ${ }^{24}$-interactions which result from unopposed adrenergic stimulation in the presence of $\beta$ blockade. For the same reason the combination of ergotamine and a non-selective $\beta$ blocker may produce severe peripheral ischaemia. ${ }^{25} 26$

$\beta$ blockers, especially non-selective ones such as propranolol, can delay recovery from hypoglycaemia induced by insulin or oral antidiabetic drugs. ${ }^{27}$ They can also interfere with the usual haemodynamic response to hypoglycaemia and produce a rise in blood pressure associated with severe bradycardia. ${ }^{28}$ The clinical importance of these effects is probably small in most diabetics, but $\beta$ blockers may best be avoided in unstable diabetics prone to episodes of hypoglycaemia.

LINDA BEELEY

Consultant Clinical Pharmacologist,

Drug and Therapeutics Unit,

Queen Elizabeth Hospital,

Birmingham B15 2TH

1 Park BK. Prediction of metabolic drug interactions involving $\beta$-adrenoceptor blocking drugs. $\mathrm{Br} f$ Clin Pharmacol 1984;17:3-10S

2 Bennet PN, John VA, Whitmarsh VB. Effects of rifampicin on metoprolol and antipyrine kinetics. Br F Clin Pharmacol 1982;13:387-91

Heagerty AM, Donovan MA, Castledon CM, Pohl JF, Patel L, Hedges A. Influence of cimetidine on pharmacokinetics of propranolol. Br Med 7 1982;282:1917-9.

4 Kirch $W$, Kohler $H$, Spahn $H$, Mutschler $E$. Interaction of cimetidine with metoprolol, propranolol, or atenolol. Lancet 1981; ii:531-2.

McLean AJ, Skews $\mathrm{H}$, Bobik A, Dudley FJ. Interaction between oral propranolol and hydralazine.

Clin Pharmacol Ther 1980;27:726-32.

pharmacokinetics of Dean S, Laugher SJ, Zaman R. The effect of hydralazine on the pharmacokinetics of three different beta-adrenoceptor antagonists. Biopharm Drug Dispos
1982;3:47-84. adrenoceptor antagonists on the pharmacokinetics of lignocaine. Br $\mathcal{F}$ Clin P harmacol 1984; 17: $21-8 \mathrm{~S}$

8 Conrad KA, Byers JM, Finley PR, Burnham L. Lidocaine elimination: effects of metoprolol and of propranolol. Clin Pharmacol Ther 1983;28:463-7.

Graham CF, Turner WN, Jones JK. Lidocaine-propranolol interactions. N Engl I Med 1981;

10 Peet $M$, Middlemiss DN, Yates RA. Propranolol in schizophrenia II. Clinical and biochemical aspects of combining propranolol with chlorpromazine. Br $\mathcal{Y}$ Psychiatry 1981;139:112-7.

Bax NDS, Lennard MS, Tucker GT, et al. The effect of $\beta$-adrenoceptor antagonists on the 1984;17:553-7.
1.5s and pharmacodynamics of warfarin after a single dose. Brf Clin Pharmacol Scott AK, Park BK, Brecken

3 Spahn H, Kirch W, Mutschler E, et al. Pharmacokinetic and pharmacodynamic interactions between phenprocoumon and atenolol or metoprolol. Brf Clin Pharmacol 1984;17:97-102S. Seabra-Gomes R, Rickards A, Sutton R. Haemodynamic effects of verapamil and practolol in man. Eur F Cardiol 1976;4:79-85.

15 Gelipter D, Hazell M. Interaction between disopyramide and practolol. Br Med $\mathcal{f} 1980 ; 280: 52$. $6 \mathrm{Ibram} \mathrm{H}$. Hemodynamic and electrophysiologic interactions between antiarrhythmic drugs and beta-blockers with special reference to tocainide. Am Heart $\mathcal{F}$ 1980;100:1076-80.

Robson RH, Vishwanath MC. Nifedipine and beta-blockade as a cause of cardiac failure. Br Med $\mathcal{J}$

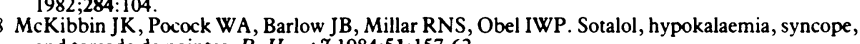
and torsade de pointes. Br Heart $\mathcal{Y}$ 1984;51: 157-62.

Watkins ], Abbott EC, Hensby CN, Webster J, Dollery CT. Attenuation of hypotensive effect of

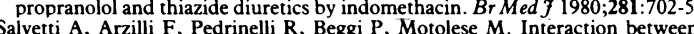

indomethacin on blood pressure in essential hypertensive patients. Eur 7 Clin Pharmacol 1982;22:197-201.

21 Salvetti A, Pedrinelli R, Alberici P, Magagna A, Abdel-Haq B. The influence of indomethacin and sulindac on some pharmacological actions of atenolol in hypertensive patients. $B r \mathcal{J}$ Clin Pharmacol 1984;17:108-11S.

22 Elliot HL, McLean K, Sumner DJ, Meredith PA, Reid JL. Immediate cardiovascular responses to oral prazosin - effect of concurrent beta-blockers. Clin Pharmacol Ther 1981;29:303-9.

Bailey RR, Neale TJ. Rapid clonidine withdrawal with blood pressure overshoot exaggerated by beta-blockade. Br Med 1976;i1:942.

Kadar D, Stein HA. Hazards of phenylephrine topical medication in persons taking propranolol. Can Med Assoc F 1979;120:1261-2.

Baumrucker

26 Venter $\mathrm{CP}$, Joubert PH, Buys AC. Severe peripheral ischaemia during concomitant use of beta-blockers and ergot alkaloids. Br Med $\mathcal{F}$ 1984;289:288-9.

7 Newman KJ. Comparison of propranolol, metoprolol and acebutolol on insulin-induced hypoglycaemia. Br Med J 1976;ii:447-9. Lloyd-Mostyn RH, Oram S. Modification by propranolol of cardiovascular effects of induced
hypoglycaemia. Lancet 1975;i:1213-5.

\section{Administrator dominated or management efficient NHS?}

A year ago the $B M \mathcal{F}$ cautiously welcomed the outcome of the National Health Service management inquiry, which was led by $\mathrm{Mr}$ Roy Griffiths, a senior executive in a successful supermarket chain. ${ }^{1}$ The Griffiths report was correct in diagnosing weaknesses in NHS management and though the report was brief and provocative the general thrust of its conclusions merited careful consideration. In the event-and despite the BMA's success in extending it-there was a far too hasty period of consultation, during which the health professions showed much less enthusiasm for the report than administrators, and the House of Commons social services committee gave lukewarm endorsement. ${ }^{2}$ Nevertheless, the government, determinedly pushing its policy of cost effectiveness in the NHS, quickly accepted it and in June a sketchy implementation circular for England appeared-the rest of the United Kingdom will follow later. ${ }^{3}$

After prolonged but eventually successful negotiations between the government and the medical profession about the terms under which clinicians should participate in management at unit level the BMA decided to go along with the government's plans. ${ }^{4}$ So the association is now urging doctors to take part in the new management structure, briefing the profession in a series of countrywide meetings (over 100 of which have been held so far). Individual doctors will now have to make up their minds whether to join the Griffiths scheme in their districts and units.

The mood of doctors in the briefing meetings has been described as nervous. This is not surprising, given the profession's anxieties over clinical independence and medical priorities and the fact that while doctors have been arguing about their future place in management administrators have been acting. The Griffiths report aimed at improving management in the NHS by identifying a clear line of responsibility from the new NHS management board down to units. General managers would be appointed or identified at regional, district, and unit levels, who would be ultimately responsible for taking decisions, seeing that they were implemented, and monitoring the outcome. So far so good: such a system is normal for commerce or industry. For it to work in the NHS, however, where much power has traditionally resided with doctors on the "shop floor" and where consensus team management was introduced in 1974 to marry the often conflicting needs of management and medicine, certain conditions are necessary. Budgeting procedures need modernising; up to date information on health service activities should be readily available; and the health professions must have an effective input into management.

Two of these conditions are in hand. Firstly, accountability reviews are already operating and functional budgeting, recommended in the Griffiths report, is being introduced. Secondly, the Körner steering group on health services information has completed a series of reports, which should, as the recommendations are introduced, contribute to more effective management. ${ }^{5}$ The third condition, however-namely, how the health professionals' views will be fed into the management process-remains a matter for conjecture. There are several uncertainties. How will clinicians (mainly consultants but including some general practitioners) appointed as unit management repre- 